\title{
Effects of Metal Phthalocyanines as Hole-transporting Layers of Perovskite-based Solar Cells
}

\author{
Atsushi Suzuki ${ }^{1, *}$, Haruka Ueda $^{1}$, Yuki Okada $^{1}$, Yuya Ohishi $^{1}$, Yasuhiro Yamasaki $^{2}$, Takeo Oku $^{1}$ \\ ${ }^{1}$ Department of Materials Science, the University of Shiga Prefecture, Japan \\ ${ }^{2}$ Department of New Business, Orient Chemical Industries Co. Ltd., Japan
}

Copyright $\bigcirc 2017$ by authors, all rights reserved. Authors agree that this article remains permanently open access under the terms of the Creative Commons Attribution License 4.0 International License

\begin{abstract}
Halogen halide perovskite solar cells using active layer of $\mathrm{CH}_{3} \mathrm{NH}_{3} \mathrm{PbI}_{3}$ with vanadyl phthalocyanine (VOPc), vanadyl naphthalocyanine (VONc) and, tetrakis (tert-butyl)[bis(trihexylsiloxy)germanium phthalocyanine] $(\mathrm{GePc})$ doped 2,2',7,7'-tetrakis-(N,N-di-4-methoxy phenyl amino)-9,9'-spirobifluorene (Spiro-OMeTAD) as holetransporting layers were fabricated and characterized for optimizing with tuning the photovoltaic performance, optical properties, and microstructure. Introducing of metal phthalocyanine into the hole-transporting layer improved the photovoltaic properties including carrier diffusion with increase of carrier mobility, optical absorption, and the perovskite crystal growth. The metal phthalocyanines had the effect of promoting optically induced carrier generation and improvement of the charge transport with suppression of carrier recombination as electron blocking layers on the photovoltaic mechanism. The energy diagram and photovoltaic mechanism are discussed by the experimental results.
\end{abstract}

Keywords Perovskite Solar Cell, X-ray Diffraction, Photovoltaic Properties, Optical Properties, Microstructure

\section{Introduction}

Fabrication and characterization of the photovoltaic and optical properties and microstructure of organic-inorganic hybrid solar cells containing the perovskite compound with mesoporous $\mathrm{TiO}_{2}$ as the electron-transporting layer and semi-conductive materials as the hole-transporting layer (HTL) was investigated [1-3]. The perovskite based solar cell have a high performance of the photovoltaic and optical properties with open circuit voltage, short circuit current, fill factor with a high efficiency of conversion. The perovskite based solar cell has a great advantage to have a simple production with a wide range of optical absorption. The perovskite solar cells consist of titanium oxide as electron transporting layer, halogen halide $\mathrm{CH}_{3} \mathrm{NH}_{3} \mathrm{PbI}_{3}$ perovskite crystal in photoactive layer and 2,2',7,7'-tetrakis-(N,N-di-4methoxyphenylamino)-9,9'-spirobifluorene (SpiroOMeTAD) as hole-transporting layer [1]. Crystal structure of iodide/chloride mixed-halide perovskites improved their photovoltaic performances [2-4]. The photovoltaic properties were based on exceed of carrier-injection from the perovskite compound as the active layer to $\mathrm{TiO}_{2}$ as the electron-transporting layer and Spiro-OMeTAD as the hole-transporting layer, and carrier-transporting behavior. The hole-transporting layer have an important role of promotion of carrier diffusion with inhibiting carrier recombination in crystal and amorphous phase pathway, electron-blocking layer, and charge transferring to cathode. For example, the photovoltaic device based on a new hole-transporting materials using quinolizino acridine compound achieved to be $12.8 \%$ as high power conversion efficiency $[5,6]$. For optimizing and tuning the photovoltaic performance, $\mathrm{CH}_{3} \mathrm{NH}_{3} \mathrm{~Pb}\left(\mathrm{I}_{1-\mathrm{x}} \mathrm{Br}_{\mathrm{x}}\right)_{3}$ halide perovskite crystal structure was controlled by solvent-engineering technology [7]. Formation of millimeter-sized $\mathrm{CH}_{3} \mathrm{NH}_{3} \mathrm{PbBr}_{3}$ and $\mathrm{CH}_{3} \mathrm{NH}_{3} \mathrm{PbI}_{3}$ single crystals improved the photovoltaic properties [8].

Photovoltaic parameters of light-harvesting efficiency and charge-carrier extraction were considerably affected by controlling deposition conditions of crystal structure, chemical composition ratio, halogen doping, holetransporting material and state of the interface $[9,10]$. Control of chemical composition ratio of cation using methyl ammonium, formamidinium and halogen dopant using chloride, bromide, iodine, lead, tin, germanium, cesium and thallium in halogen halide perovskite structure and titanium oxide layers as electron transporting material was investigated for improving the photo-induced carrier-generation, charge transport, surface morphology, and crystal growth. [11-15]. Morphological observation of the $\mathrm{CH}_{3} \mathrm{NH}_{3} \mathrm{PbX}_{3}$ crystal structure also revealed the formation of rhombo-hexagonal dodecahedra crystallite for $\mathrm{X}=\mathrm{I}, \mathrm{Br}$, whereas cube-like aggregates were obtained for $\mathrm{X}$ $=\mathrm{Cl}$. [16]. Incorporation of $\mathrm{Cl}$ into lead halide perovskite film influenced the morphological behavior and the 
photovoltaic performance [17]. Experimental and theoretical investigation also expected electronic and optical properties of the perovskite system $[18,19]$. Role of halogen doping using $\mathrm{I}, \mathrm{Br}, \mathrm{Cl}$, cesium $(\mathrm{Cs})$, antimony $(\mathrm{Sb})$, niobium $(\mathrm{Nb})$ compounds as dopants on the photovoltaic performance and crystalline structures of perovskite solar cells based on a mixed-halide $\left[\mathrm{HC}\left(\mathrm{NH}_{2}\right)_{2}\right]_{0.83} \mathrm{Cs}_{0.17} \mathrm{~Pb}\left(\mathrm{I}_{0.6} \mathrm{Br}_{0.4}\right)_{3}[20,21]$ and $\mathrm{CH}_{3} \mathrm{NH}_{3} \mathrm{PbI}_{3-\mathrm{x}-\mathrm{y}} \mathrm{Br}_{\mathrm{x}} \mathrm{Cl}_{\mathrm{y}}$ [22-30] compositions were investigated in detail. Experimental and theoretical investigations of mixed-halide perovskite based solar cells have been continued [31].

New-type of hole-transporting layers using organic semi-conductive materials instead of Spiro-OMeTAD in perovskite-based solar cells have been developed for improving carrier mobility and air-stability with a long life of moisture-resistivity under atmosphere condition $[32,33]$. For example, alternative hole-transporting materials using a spiro [fluorene-9, 9'-xanthene] based HTM (X59) was used for improving the photovoltaic performance [33]. The perovskite-based solar cells using conjugated organic semi-conductor with a narrow band gap as the holetransporting layer achieved to be high power conversion efficiency of $12.8 \%$ [34]. Metal phthalocyanines (MPc) as organic semi-conductor have great potential to play a role of carrier-transporting layer and optical properties with a wide range of wavelength [35-38]. The metal phthalocyanines have a promoting effect of photo-induced carrier generation, improvement of hole-transporting properties as electron blocking layers on the photovoltaic properties. The metal phthalocyanines have great advantages to work carrier transporting layer and photo-active layer by deposition process, crystal structure and modification of molecular structures with central metals and chemical substitutions. Recently, the metal phthalocyanines have been applied for organic semiconducting devices such as organic field effect transistor, catalyst for fuel cells and organic solar cells.

Many studies on metal phthalocyanines modified using central metals and chemical substitution have been reported for application of photovoltaic and optical devices. For example, the perovskite-based solar cells with copper phthalocyanine as hole-transporting layers were fabricated for improving charge extraction and charge recombination suppression [39-41]. The perovskite-based solar cells with copper phthalocyanine as hole-transporting layer achieved a power conversion efficiency of $15 \%$. Thermally evaporated phthalocyanines were applied as an excellent holetransporting material in the perovskite solar cells [42]. For example, shuttle-cock type of metal phthalocyanines such as titanyl phthalocyanine (TiOPc), lead phthalocyanine ( $\mathrm{PbPc})$, and vanadyl phthalocyanine (VOPc) have an advantage to apply for hole-transporting material with a wide range of wavelength. The shuttle-cock types of metal phthalocyanine have a change of semi-conductive properties on phase transition between $\mathrm{H}$ and $\mathrm{J}$-aggregation. The phase transition between $\mathrm{H}$ and J-aggregates remarkably influenced the electronic structure and transporting properties [43-46].
Controlling of crystal structure, domain size with preventing formation of coagulation and aggregates is important factor for optimizing and tuning the carrier mobility and optical properties with near-infrared absorption band in the organic solar cells. Especially, soluble metal phthalocyanine with bulky type of chemical groups will have advantage to improve the aggregation, the film-forming ability and carrier transporting behavior without carrier recombination.

The purpose of this study is to investigate effects of metal phthalocyanines with vanadyl phthalocyanine (VOPc) and tetrakis(tert-butyl)[bis(trihexylsiloxy)germanium

phthalocyanine] $(\mathrm{GePc})$ as hole-transporting materials (HTM) on the perovskite-based solar cell. The photovoltaic properties are investigated by $J-V$ curves under light irradiation, external quantum efficiency (EQE) and optical absorption. The perovskite crystal structures, surface morphology varying with composition ratio of lead and iodine are measured by X-ray diffraction, scanning electron microscopy and energy dispersive X-ray spectroscopy. Promoting effects of photo-induced carrier generation and improvement of the hole-transporting properties as electron blocking layers on the photovoltaic properties of the perovskite based solar cells with metal phthalocyanines are investigated. The energy diagram and the photovoltaic mechanism are discussed to enable optimization with the improvement of photovoltaic properties, optical absorption and microstructure.

\section{Materials and Methods}

Fluorine-doped tin-oxide (FTO)-coated glass substrates were cleaned in an ultrasonic bath with acetone and methanol and dried under nitrogen gas. The $0.15 \mathrm{M} \mathrm{TiO}_{2}$ precursor solution was prepared from titanium diisopropoxide bis(acetylacetonate) (55 $\mu \mathrm{L}$, Sigma Aldrich Japan K. K., Tokyo, Japan) in 1-butanol (1 mL), and the $\mathrm{TiO}_{2}$ precursor solution was spin-coated on the FTO substrate at $3000 \mathrm{rpm}$ for $30 \mathrm{~s}$ and annealed $125{ }^{\circ} \mathrm{C}$ for 5 min. Afterwards, the coated film was cooled to room temperature, the same process was repeated twice with 0.3 $\mathrm{M}$ titanium diisopropoxide bis(acetylacetonate) solution in 1-butanol at $3000 \mathrm{rpm}$. The coated FTO glasses with $\mathrm{TiO}_{2}$ precursor solutions were heated at $500{ }^{\circ} \mathrm{C}$ for $30 \mathrm{~min}$ to form the compact $\mathrm{TiO}_{2}$ layer. A mesoporous $\mathrm{TiO}_{2}$ layer was deposited by spin-coating at $5000 \mathrm{rpm}$ for $30 \mathrm{~s}$. $\mathrm{TiO}_{2}$ paste was prepared with $\mathrm{TiO}_{2}$ powder (Aerosil P-25, Nippon Aerosil Co. Ltd, Tokyo, Japan) with poly(ethylene glycol) (PEG \#20000, Nacalai Tesque Inc. Kyoto, Japan) in ultrapure water. The solution was mixed with acetyl acetone (10.0 $\mu$ L, Wako Pure Chemical Industries, Osaka, Japan) and Triton X-100 (5 $\mu$ L, Sigma Aldrich Japan K. K., Tokyo, Japan) for $30 \mathrm{~min}$. For preparing the $\mathrm{TiO}_{2}$ film with anatase crystal phase, the layers were annealed at $500{ }^{\circ} \mathrm{C}$ for 30 $\min$.

For the preparation of pigment with a perovskite structure, a solution of methyl ammonium iodide $\left(\mathrm{CH}_{3} \mathrm{NH}_{3} \mathrm{I}\right)$ (Showa 
Chemical Co. Ltd., Tokyo, Japan) and $\mathrm{PbI}_{2}$ (Sigma Aldrich) in $\gamma$-butyrolactone (Nacalai Tesque, Inc. Kyoto, Japan) was mixed at $70^{\circ} \mathrm{C}$. The solution was then dropped into the $\mathrm{TiO}_{2}$ mesoporous structure by spin-coating method, and annealing was performed to promote the crystal growth at $100^{\circ} \mathrm{C}$ for $15 \mathrm{~min}$. Molecular structures of hole- transporting materials are shown in Figure 1. Thin film of shuttle cock-type of phthalocyanine such as vanadyl phthalocyanine (VOPc, Kanto Chemical Co. Inc. Tokyo, Japan), and vanadyl naphthalocyanine (VONc, Sigma Aldrich Japan K. K., Tokyo, Japan) as hole-transporting layer (HTL) was deposited on the ITO/TiO $/ \mathrm{CH}_{3} \mathrm{NH}_{3} \mathrm{PbI}_{3}$ by evaporation $\left(1.2 \times 10^{-3} \mathrm{~Pa}\right)$.

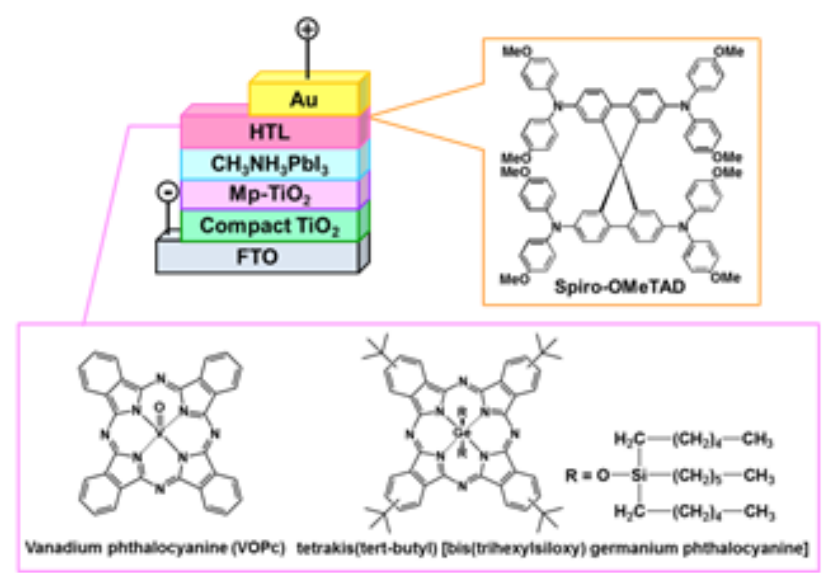

Figure 1. (a) Perovskite solar cells and molecular structure of (b) spiro-OMeTAD, (c) VOPc and (d) GePc as hole-transporting materials.

The spiro-OMeTAD solution was prepared as follows. The mixture of spiro-OMeTAD $(36.1 \mathrm{mg}$ Wako Pure Chemical Industries, Osaka, Japan) in $0.5 \mathrm{~mL}$ chloroform with tetrakis(tert-butyl)[bis(trihexylsiloxy)germanium phthalocyanine] (GePc) at $6.7 \mathrm{wt} \%$ and $12.6 \mathrm{wt} \%$ was mixed for overnight. The spiro-OMeTAD solution with 4-tert-butyl pyridine (14.4 $\mu \mathrm{L}$ Sigma-Aldrich Japan K. K., Tokyo, Japan) and powder of lithium bis(trifluoromethyl sulphonyl) imide (Li-TFSI) in acetonitrile $8.8 \mu \mathrm{L}$ was mixed with a magnetic stirrer for $30 \mathrm{~min}$. at $70^{\circ} \mathrm{C}$. The mixed solution was spin-coated on the ITO/TiO $/ \mathrm{CH}_{3} \mathrm{NH}_{3} \mathrm{PbI}_{3}$ at $1000 \mathrm{rpm}$ for $5 \mathrm{~s}$, then at $3000 \mathrm{rpm}$ for $30 \mathrm{~s}$. The gold $(\mathrm{Au})$ top electrode was thermally evaporated through a stainless steel mask with an area of $0.090 \mathrm{~cm}^{2}(0.3 \mathrm{~cm} \times 0.3 \mathrm{~cm})$. In a similar way of cited references [23, 24, 35], layered structures of the present photovoltaic cells of $\mathrm{FTO} / \mathrm{TiO}_{2} / \mathrm{CH}_{3} \mathrm{NH}_{3} \mathrm{PbI}_{3} / \mathrm{HTL} / \mathrm{Au}$ were fabricated, as schematically illustrated in Figure. 2.

The current density-voltage $(J-V)$ characteristics of the photovoltaic solar cells were measured both in the dark and under illumination at $100 \mathrm{~mW} \mathrm{~cm}^{-2}$ (Air mass AM1.5) using an AM1.5 solar simulator (XES-301S, San-ei Electric Co. Ltd., Osaka, Japan) and a potentiostat (HSV-110, Hokuto Denko Corporation, Tokyo, Japan). The solar cells were illuminated through the side of the FTO substrate. The illuminated areas were $0.090 \mathrm{~cm}^{2}(0.3 \mathrm{~cm} \times 0.3 \mathrm{~cm})$, and power conversion efficiency (PCE) was measured. The photocurrent curve was observed under illumination, and showed characteristic curves with regard to the short-circuit current density $\left(J_{S C}\right)$ and open-circuit voltage $\left(V_{O C}\right)$. The experimental parameters of forward scan rate, starting and last voltage were fixed to be $100 \mathrm{mV} \mathrm{s}^{-1},-0.2 \mathrm{~V}$ and $1.0 \mathrm{~V}$, respectively. Without holding at constant time of the device under illumination in ambient condition, the once scanning of $J-V$ curve measurement was performed in the range of forward voltage from $-0.2 \mathrm{~V}$ to $1.0 \mathrm{~V}$. The hysteresis measurement of photocurrent density with forward and backward voltage was not performed for investigating the transient phenomena. The photovoltaic characteristics were depending on the film preparation and measurement conditions. Repeated measurements of $J-V$ curve were performed for obtaining an average and highest values. The detailed parameters of the device are listed in Table 1.

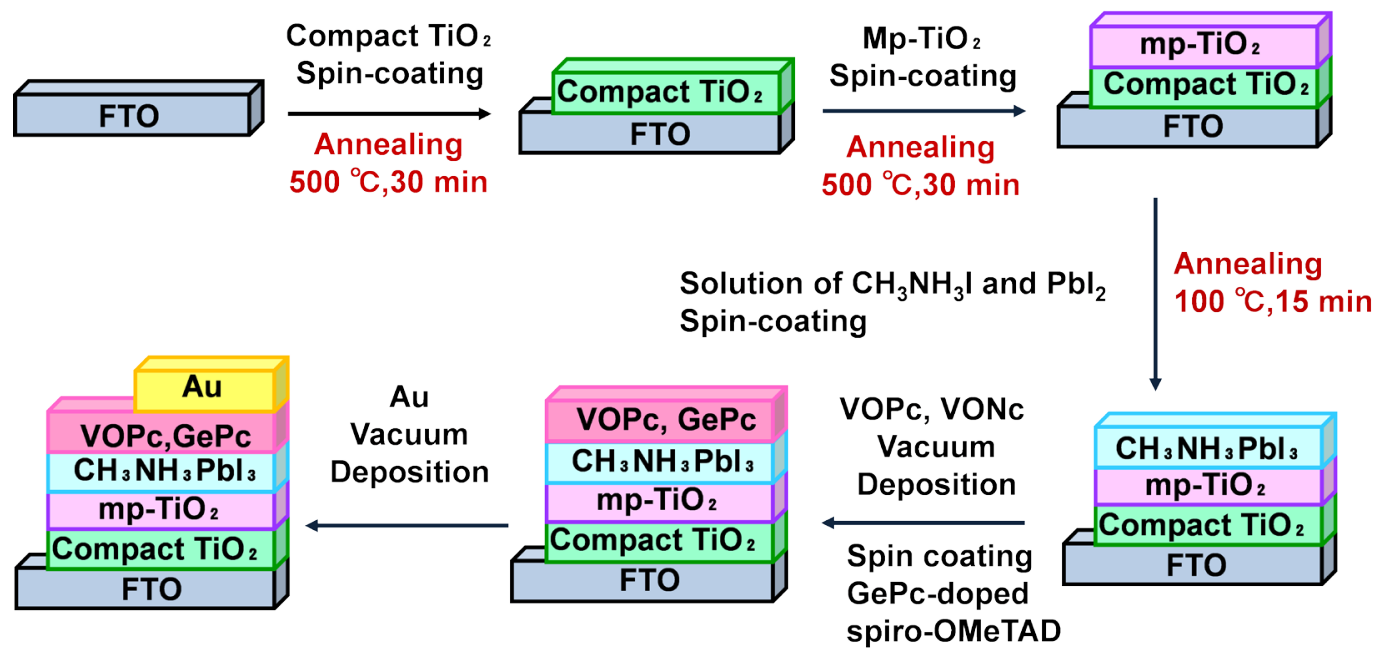

Figure 2. Fabrication of $\mathrm{FTO} / \mathrm{TiO}_{2} /$ perovskite/HTL/Au solar cells. HTL: VOPc, VONc and GePc-doped spiro-OMeTAD. 
Table 1. The photovoltaic parameters of the FTO/TiO $/$ /perovskite/HTL/Au perovskite solar cells. (HTL: VOPc, VONc, GePc doped spiro-OMeTAD). The highest values of PCE out of the brackets. The averages values in brackets

\begin{tabular}{|c|c|c|c|c|}
\hline Hole-transporting layer & $J_{S C}\left(\mathrm{~mA} \mathrm{~cm}^{-2}\right)$ & $V_{O C}(\mathrm{~V})$ & FF & PCE $(\%)$ \\
\hline w/o HTL & $8.55(9.25)$ & $0.21(0.16)$ & $0.32(0.32)$ & $0.59(0.49)$ \\
\hline VOPc & $11.26(9.84)$ & $0.76(0.72)$ & $0.28(0.31)$ & $2.44(2.22)$ \\
\hline VONc & $11.45(11.20)$ & $0.81(0.79)$ & $0.30(0.28)$ & $2.81(2.29)$ \\
\hline Spiro-OMeTAD & $10.45(10.13)$ & $0.79(0.78)$ & $0.51(0.50)$ & $4.23(4.00)$ \\
\hline Spiro-OMeTAD + GePc (12.5 wt \%) & $15.81(14.55)$ & $0.74(0.72)$ & $0.46(0.42)$ & $4.47(4.36)$ \\
\hline
\end{tabular}
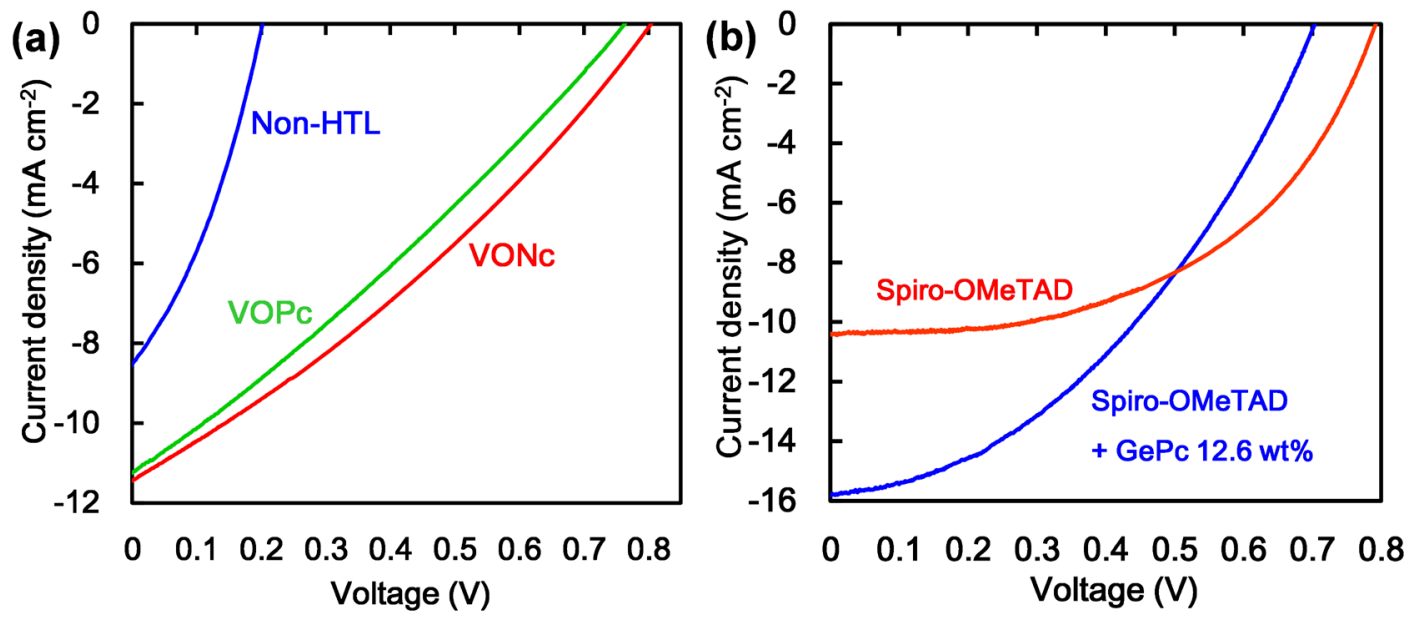

Figure 3. A $J-V$ characteristics of the perovskite based solar cells with (a) VOPc, VONc and (b) GePc doped spiro-OMeTAD as hole-transporting layer.

Optical absorption properties were measured by ultraviolet-visible-near-infrared spectroscopy (Jasco V-670, Jasco Corporation, Tokyo, Japan). X-ray diffraction measurements were performed (Bruker D2 PHASER, Bruker Corporation, Billerica, MA, United States) with a monochromatic $\mathrm{Cu} \mathrm{K} \alpha$ X-ray source $(\lambda=0.15418 \mathrm{~nm})$. Surface morphologies were observed by optical microscopy (Nikon eclipse E600, Nikon Corporation, Tokyo, Japan) and analytical scanning electron microscopy (JEOL JSM-6010 PLUS/LA, JEOL Ltd. Tokyo, Japan). Atomic composition on the perovskite layer in the solar cells was analyzed by energy dispersive X-ray spectroscopy (EDX). The external quantum efficiency (EQE) values of the solar cells were measured (Enlitech QE-R3011, Enlitech Technology Co. Ltd. Kaohsiung, Taiwan). The device active area for all the solar cells was $0.090 \mathrm{~cm}^{2}$.

\section{Results and Discussion}

The photovoltaic properties of the perovskite-based solar cell with VOPc, VONc, and GePc-doped spiro-OMeTAD as hole-transporting layer were investigated. The $J-V$ characteristics of the perovskite-based solar cells with hole-transporting layer of VOPc, VONc, and GePc-doped spiro-OMeTAD are shown in Fig. 3 (a) and (b). The photocurrent current was observed under illumination, and showed characteristic curves with regard to the short-circuit current density $\left(J_{S C}\right)$ and open-circuit voltage $\left(V_{O C}\right)$. The detailed parameters of the best device are listed in Table 1. The photovoltaic parameters of $J_{S C}, V_{O C}$, fill factor (FF) and overall power conversion efficiency (PCE) were obtained to be $11.26 \mathrm{~mA} \mathrm{~cm}^{-2}, 0.76 \mathrm{~V}, 0.28,2.44 \%$ for VOPc and 11.45 $\mathrm{mA} \mathrm{cm}{ }^{-2}, 0.81 \mathrm{~V}, 0.30,2.81 \%$ for VONc, respectively. The photovoltaic parameters of $J_{S C}, V_{O C}, \mathrm{FF}$, and PCE in the VOPc and VONc were improved as compared with non-additive case. Introducing of $\mathrm{VOPc}$ and $\mathrm{VONc}$ into HTL improved the photovoltaic performance including carrier diffusion with increase of carrier mobility as well as $J_{s c}$ with repression of carrier re-combination and leak current near interface between HTL and the perovskite crystal domains in the microstructure. The photovoltaic properties of the perovskite-based solar cell with GePc-doped spiro-OMeTAD are shown in Fig. 3 (b). Additive effects of GePc-doped spiro-OMeTAD as hole-transporting layer on the photovoltaic properties of the perovskite-based solar cell were investigated. In the presence of GePc-doped into spiro-OMeTAD, the photovoltaic parameters of $J_{s c}, V_{o c}, \mathrm{FF}$, and PCE were obtained to be $15.8 \mathrm{~mA} \mathrm{~cm}-2,0.74 \mathrm{~V}, 0.46$, and $4.5 \%$, respectively. In the case of spiro-OMeTAD as reference, the photovoltaic parameters of $J_{s c}, V_{o c}, \mathrm{FF}$, and PCE were obtained to be $10.45 \mathrm{~mA} \mathrm{~cm}^{-2}, 0.79 \mathrm{~V}, 0.51$, and $4.2 \%$, respectively. Introducing GePc doped into spiro-OMeTAD improved the photovoltaic parameters of $J_{S C}, V_{O C}$ and PCE.

In the standard case, fabrication and characterization of the perovskite solar cell was repeatedly performed for confirmation of reproducibility. The low conversion with producing sub-reaction of $\mathrm{PbI}_{2}$ would be caused by degradation with hydrolysis reaction under humidity. Exposure of the perovskite crystal to light and humidity would result in the decomposition to $\mathrm{PbI}_{2}$. While the film preparation and measurements of the $J-V$ curve for the perovskite solar cells were performed under atmosphere 
condition, the photovoltaic parameters of $J_{s c}, V_{o c}, \mathrm{FF}$, and PCE were influenced by the film preparation condition at normal humidity, such as $40-65 \%$. Effect of atmospheric humidity on the photovoltaic performance, carrier generation, charge separation and crystallization in the perovskite films has been investigated. The performance of $V_{o c}, \mathrm{FF}$ and PCE for the perovskite solar cell would be originated from a low degree of crystallinity with carrier loss and leak current near interface between the crystal domains in the microstructure. Optimization under the film preparation in a globe box filled with a high purity inert gas will improve the photovoltaic performance of $J_{s c}, V_{o c}, \mathrm{FF}$, and PCE.

Effects of VOPc and VONc on optical properties and $\mathrm{EQE}$ were also investigated. Optical absorption is shown in Fig. 4 (a) and (b). In the case of $\mathrm{FTO} / \mathrm{TiO}_{2} /$ perovskite/ VOPc and VONc, absorption for VOPc was assigned to be Soret band and Q-band near $300 \mathrm{~nm}, 600 \mathrm{~nm}$, and $780 \mathrm{~nm}$. Absorption for VONc was assigned to be in the range of 700-900 nm, which was identified to be Q-band transition. Addition of VOPc and VONc expanded the optical wavelength in a wide range of 300-920 nm. In the both case, the spectra in the range of $500-850 \mathrm{~nm}$ were identified as perovskite layer. The optical absorption of $\mathrm{FTO} / \mathrm{TiO}_{2} /$ perovskite/GePc-doped spiro-OMeTAD was not measured due to insufficient quantity of GePc for experiment.

Additive effects of GePc-doped spiro-OMeTAD as the hole-transporting layer on the performance and EQE were investigated. Relationship between wavelength and the value of EQE of the perovskite solar cells with GePc-doped spiro-OMeTAD are shown in Fig. 5. The performance of $\mathrm{EQE}$ in the $\mathrm{FTO} / \mathrm{TiO}_{2} /$ perovskite/GePc-doped spiro$\mathrm{OMeTAD} / \mathrm{Au}$ perovskite solar cells was increased to be about $15 \%$ in the range of $350-400 \mathrm{~nm}$ as the Soret band transition. Addition of $\mathrm{GePc}$ promoted photo-induced carrier generation and carrier transporting behavior with suppression of carrier recombination.

Introducing of VOPc, VONc and GePc-doped spiroOMeTAD layer played an important role of producing carrier diffusion in the hole-transport layer, not charge separation in the layer. There would exist a uniformly distribution of GePc in the spiro-OMeTAD phase. The perovskite crystal growth would improve the photovoltaic performance to promote carrier diffusion with transporting through the charge path in the homogeneous phase.
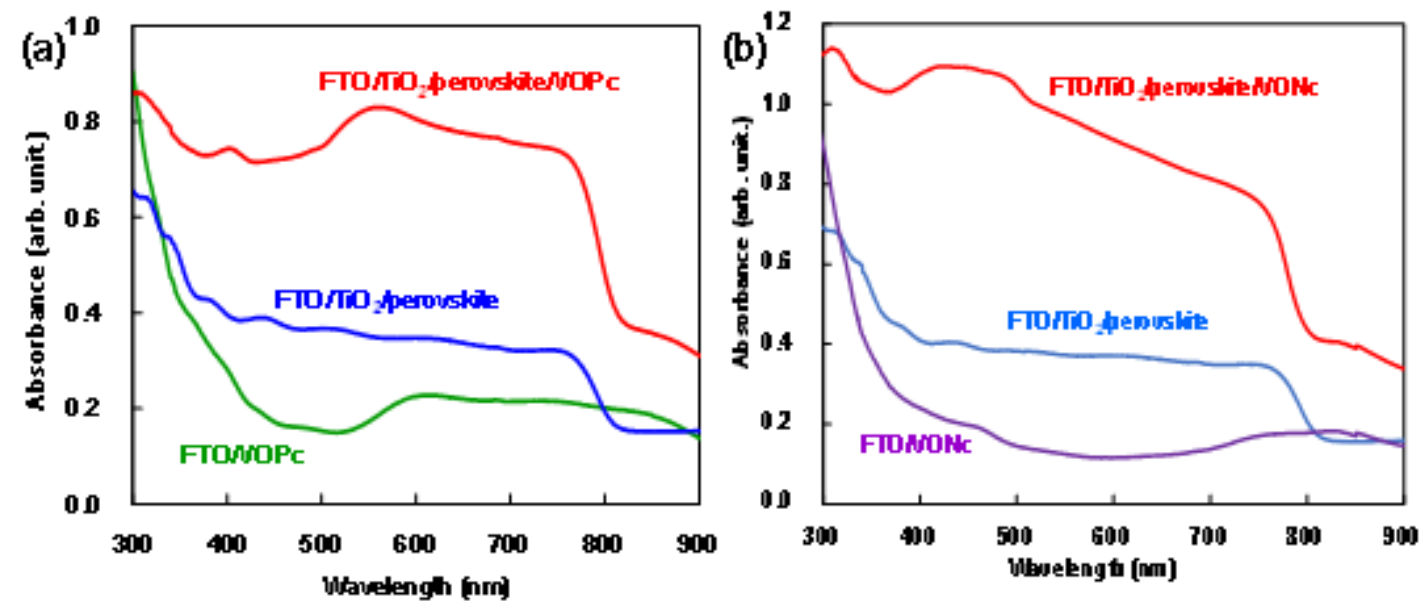

Figure 4. Optical absorbance of (a) $\mathrm{FTO} / \mathrm{TiO}_{2} /$ perovskite/VOPc and (b) $\mathrm{FTO} / \mathrm{TiO}_{2} /$ perovskite/VONc cells.

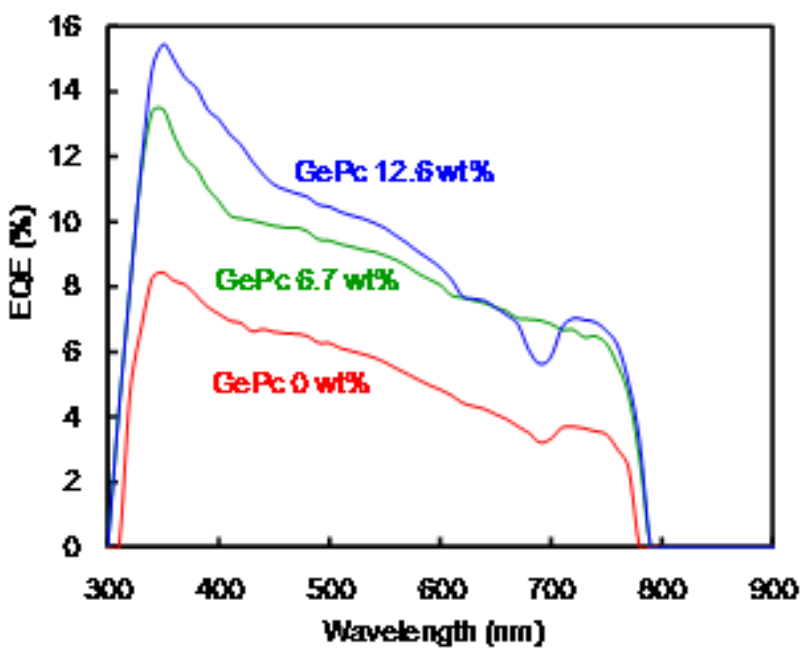

Figure 5. EQE of $\mathrm{FTO} / \mathrm{TiO}_{2} /$ perovskite/HTL cells. HTL: GePc-doped spiro-OMeTAD. 
$\mathrm{X}$-ray diffraction patterns of the $\mathrm{FTO} / \mathrm{TiO}_{2} /$ perovskite/ HTL/Au perovskite solar cells are shown in Fig. 6. Effect of VOPc, VONc and GePc doped spiro-OMeTAD as the hole-transporting layer on the perovskite crystal growth and size was investigated as shown in Fig. 6 (a) and (b). The diffraction patterns of perovskite crystal, $\mathrm{PbI}_{2}$, and $\mathrm{TiO}_{2}$ were identified as remarks. First strength of diffraction peak near 14 degree was confirmed to be (100) crystal plane in cubic crystal structure. The crystallite size for VOPc and VONc system was increased to be about 50.3 and $53.9 \mathrm{~nm}$, as compared with that of $49.7 \mathrm{~nm}$ in the absence of HTL. Deposition of VOPc and VONc on the photoactive layer provided a slight acceleration of the perovskite crystal growth with increase of crystal size, which yielded improvement of carrier transporting behavior with carrier suppression and the photovoltaic performance. In the reference case without HTL, the crystal growth would be inhibited to become a low photovoltaic performance under crystal quenching condition. As shown in Fig. 6 (b), X-ray diffraction pattern of the $\mathrm{FTO} / \mathrm{TiO}_{2} /$ perovskite/GePc-doped spiro-OMeTAD layer indicated that d-spacing was slightly widen to be about $0.36 \mathrm{~nm}$, crystal size was decreased to be about $80.0 \mathrm{~nm}$. Addition of GePc-doped spiro-OMeTAD also influenced the perovskite crystal growth, size and the photovoltaic properties.

Optical images of the perovskite solar cells using VOPc, VONc, spiro-OMeTAD and GePc-doped spiro-OMeTAD as hole-transporting layer are shown in Fig. 7. In the case of VOPc and VONc, the perovskite crystal was unevenly grown and became a larger size in sub-regions. The perovskite layer deposited with the VOPc and VOPc thin-film had the heterogeneous crystallization in the deposition process. In the case of GePc-doped spiro-OMeTAD, the perovskite crystal was grown in the range of 5-10 $\mu \mathrm{m}$. In the case of GePc-doped spiro-OMeTAD, recrystallization, the crystal nucleation and growth in the perovskite layer occurred under solvent evaporation. Promotion of the recrystallization would improve the photovoltaic parameters of short-circuit current density, carrier diffusion and carrier lifetime without carrier recombination near crystal interface in the microstructure.

Surface morphologies and elemental mapping images of the perovskite crystal structure were observed by surface analysis using scanning electron microscope and energy dispersive X-ray spectroscopy. The uniform distribution of $\mathrm{Pb}, \mathrm{I}$ and $\mathrm{V}$ atoms on the perovskite crystal structure was identified. The atomic composition with molar ratio of $\mathrm{Pb}$ and I was decreased to be 1:2, as compared with ideal molar ratio of $\mathrm{Pb}$ and $\mathrm{I}$ at 1:3. The halogen iodine would exit from the perovskite crystal. The halogen doping of I diffused in the crystal structure with promoting the crystal growth, deteriorating the photovoltaic performance of $J_{s c}$ and PCE.

The photovoltaic mechanism of the perovskite based solar cell using active layer of $\mathrm{CH}_{3} \mathrm{NH}_{3} \mathrm{PbI}_{3}$ with VOPc, VONc, and GePc-doped spiro-OMeTAD is discussed on the basis of energy levels between valence band and conduction band, as shown in Fig. 8. Light irradiation induced to generate and separation of charge in the $\mathrm{CH}_{3} \mathrm{NH}_{3} \mathrm{PbI}_{3}$ active layer. The excited electrons of $\mathrm{CH}_{3} \mathrm{NH}_{3} \mathrm{PbI}_{3}$ in the conducting band slightly diffused and charges transferred from $\mathrm{CH}_{3} \mathrm{NH}_{3} \mathrm{PbI}_{3}$ to $\mathrm{TiO}_{2}$ on the active layer at an FTO substrate, and holes in the valence band passed through VOPc, VONc, and GePc-doped in spiro-OMeTAD layer and arrived at the Au cathode. An energy barrier exists at the semi-conductor-metal interface. The parameters of $V_{o c}$ of the perovskite-based solar cells are related to the energy gap between valence band of $\mathrm{CH}_{3} \mathrm{NH}_{3} \mathrm{PbI}_{3}$ and the conduction band of $\mathrm{TiO}_{2}$.
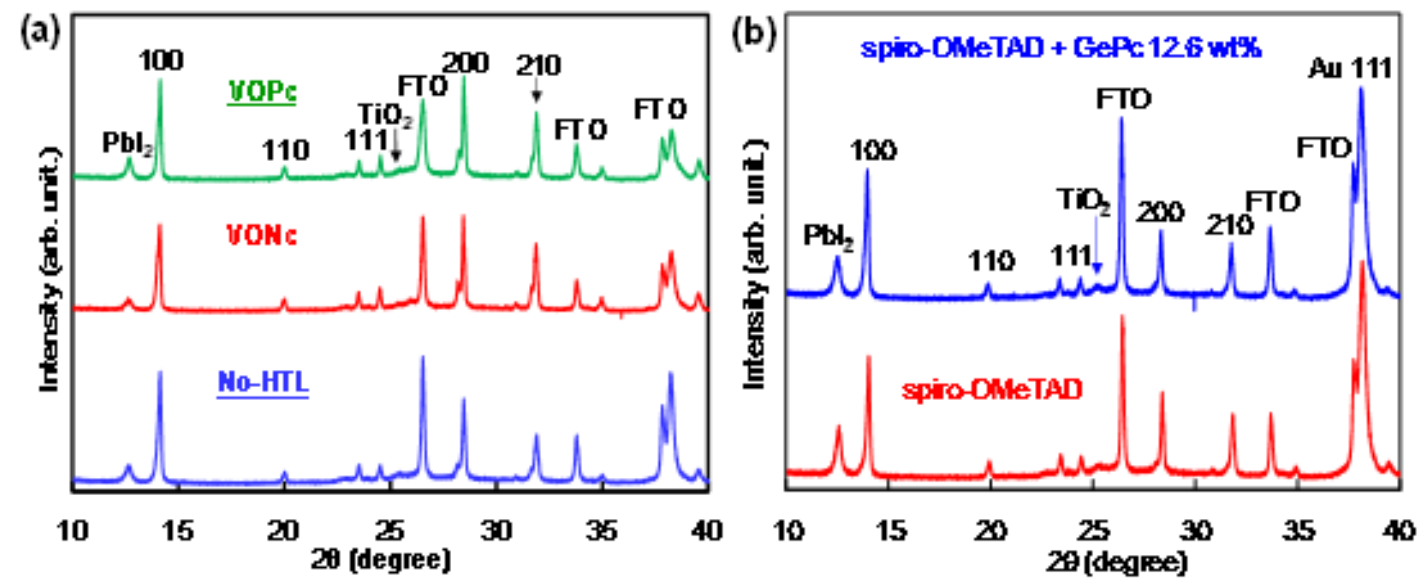

Figure 6. X-ray diffraction patterns of the $\mathrm{FTO} / \mathrm{TiO}_{2} /$ perovskite/HTL perovskite solar cells. HTL: (a) VOPc, VONc, and (b) GePc doped spiro-OMeTAD. 

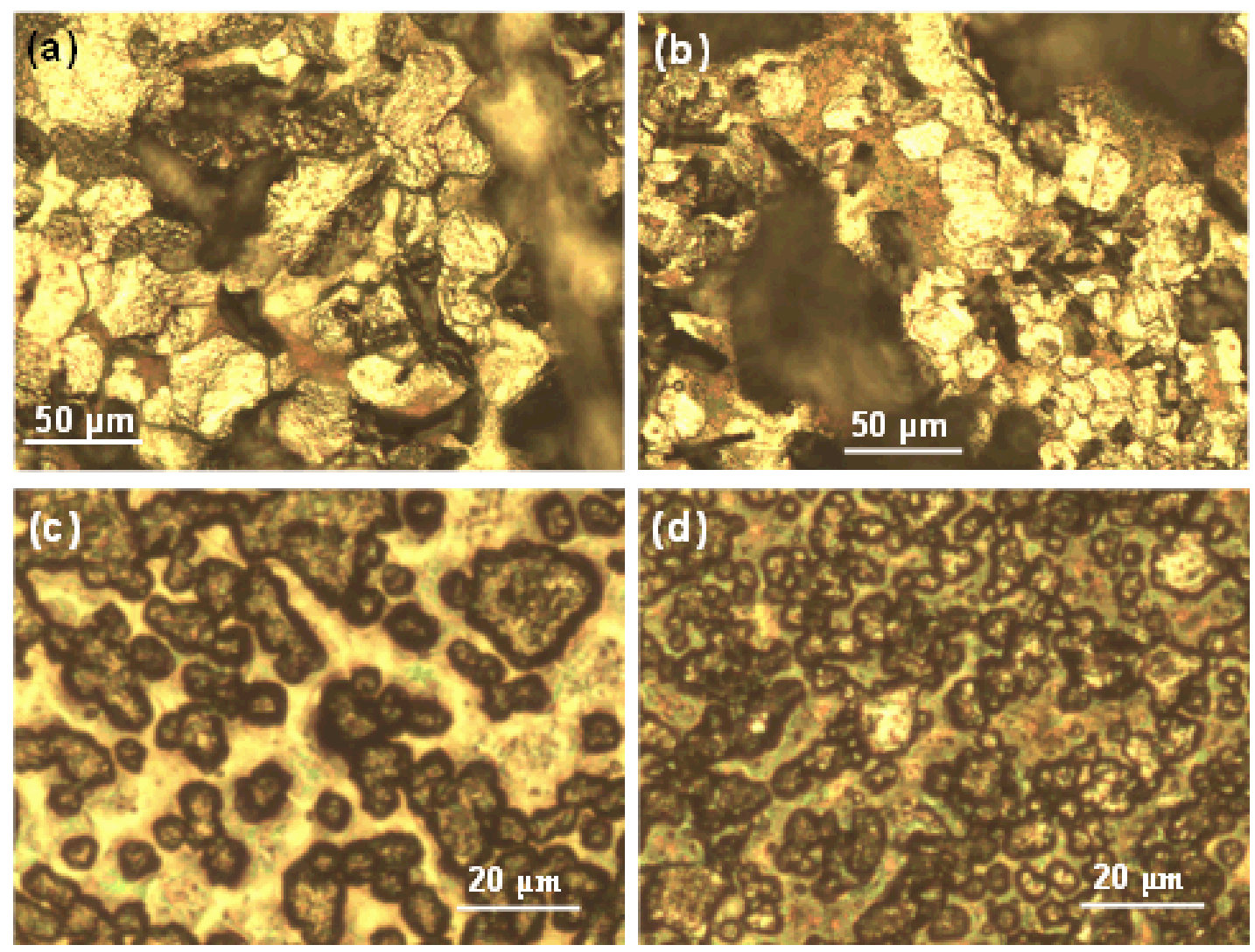

Figure 7. Optical images of the perovskite solar cells with (a) VOPc, (b) VONc, (c) spiro-OMeTAD and (d) 12.6 wt $\%$ GePc-doped spiro-OMeTAD as the hole-transporting layers.

The control of the energy levels at the valence and conduction bands in the $\mathrm{CH}_{3} \mathrm{NH}_{3} \mathrm{PbI}_{3}$ layer optimized the photovoltaic performances as well as the conversion efficiency. In addition, introducing of VOPc, VONc, and GePc-doped in spiro-OMeTAD as the hole-transport layer improved current density and conversion efficiency. The photovoltaic performance depends on band gap, carrier diffusion, and carrier recombination around interface between the perovskite layer and the hole-transporting layer. The doping condition with a small amount of VOPc, VONc, and GePc-doped in spiro-OMeTAD influenced the crystal growth of the perovskite structure for improving the carrier diffusion without recombination. The addition of VOPc, VONc, and GePc-doped spiro-OMeTAD have important roles of the carrier generation, controlling of band gap, and transporting properties as electron blocking layer with suppression of carrier recombination on the photovoltaic properties.

The soluble metal phthalocyanine with bulky types of chemical group has advantages to disperse and restrain quenching with recombination of carriers in the hole-transporting layer. The uniform dispersion state of the metal phthalocyanine in the hole-transporting layer improved the hole-transporting properties as electron blocking layer with extension of carrier lifetime in diffusion process. The perovskite-based solar cell with the metal phthalocyanine doped into hole-transporting layer has a high potential to apply the photovoltaic device with a high performance of the photovoltaic properties and conversion efficiency in practical situation.

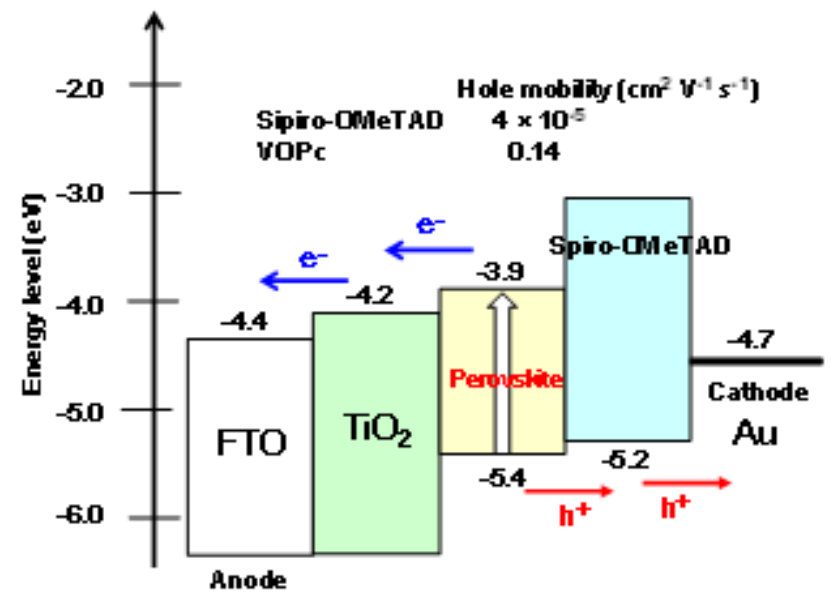

Figure 8. Energy diagram and photovoltaic mechanism of the perovskite solar cells

\section{Conclusions}

The perovskite-based solar cells with VOPc, VONc, and GePc-doped spiro-OMeTAD were fabricated and characterized for improving the photovoltaic performance, optical properties, and carrier transporting behavior. Role of VOPc, VONc, and GePc doped into spiro-OMeTAD as the 
hole-transporting layers on the photovoltaic properties and carrier diffusion was characterized. Effects of metal phthalocyanines using VOPc, VONc, and GePc-doped spiro-OMeTAD on the photovoltaic, optical properties, and crystal structures of the perovskite-based solar cells were investigated in detail. The photovoltaic performance of $J_{s c}$, $V_{o c}, \mathrm{FF}, \mathrm{PCE}$, optical wavelength, and crystalline structure were improved by addition of VOPc, as compared with the cell device in the absence of HTM. Also, doping of GePc into spiro-OMeTAD improved the photovoltaic parameters of $J_{s c}, V_{o c}, \mathrm{FF}$, and PCE by the promoting of crystal growth with a slight increase of the perovskite crystal size. Optical observation and the X-ray diffraction pattern confirmed the $\mathrm{CH}_{3} \mathrm{NH}_{3} \mathrm{PbI}_{3}$ perovskite crystal structure. Incorporation of $\mathrm{GePc}$ in spiro-OMeTAD promoted the photo-induced carrier generation and carrier diffusion with suppressing carrier recombination in the perovskite crystal domains for optimization of energy levels, band gap, and wavelength. The photovoltaic mechanism of the perovskite solar cells with metal phthalocyanine as the hole- transporting layer was discussed to enable optimization with the improvement of photovoltaic properties and optical absorption. The soluble metal phthalocyanines with bulky type of chemical group have advantage to disperse and quench with carrier recombination in the hole-transporting layer. The uniform dispersion state in the hole-transporting layer would improve carrier mobility with extension of carrier lifetime in diffusion process. The perovskite-based solar cell with the metal phthalocyanine doped into the hole-transporting layer has a high potential to apply the photovoltaic device with a high performance of conversion efficiency in practical situation.

\section{Acknowledgements}

This work was supported by Super Cluster Program of Japan Science and Technology Agency (JST), and JSPS KAKENHI Grant Number JP26390047.

\section{REFERENCES}

[1] J. H. Heo, S. H. Im, J. H. Noh, T. N. Mandal, C. S. Lim, J. A. Chang, Y. H. Lee, H. J. Kim, A. Sarkar, M. K. Nazeeruddin, M. Grätzel, S. I. 1. Seok, Efficient inorganic-organic hybrid heterojunction solar cells containing perovskite compound and polymeric hole conductors, Nat. Photonics Vol.7, 486-491, 2013.

[2] S. Colella, E. Mosconi, P. Fedeli, A. Listorti, F. Gazza, F. Orlandi, R. Ferro, T. Besagni, A. Rizzo, G. Calestani, G. Gigli, F. D. Angelis, R. Mosca, $\mathrm{MAPbI}_{3}-{ }_{\mathrm{x}} \mathrm{Cl}_{\mathrm{x}}$ Mixed halide perovskite for hybrid solar cells: The role of chloride as dopant on the transport and structural properties, Chem. Mater. Vol.25, 4613-4618, 2013.

[3] T. Oku, M. Zushi, Y. Imanishi, A. Suzuki, K. Suzuki, Microstructures and photovoltaic properties of perovskite-type $\mathrm{CH}_{3} \mathrm{NH}_{3} \mathrm{PbI}_{3}$ compounds, Appl. Phys. Express Vol.7, 121601, 2014.

[4] M. Zushi, A. Suzuki, T. Akiyama, T. Oku, Fabrication and Characterization of $\mathrm{TiO}_{2} / \mathrm{CH}_{3} \mathrm{NH}_{3} \mathrm{PbI}_{3}$-based Photovoltaic Devices, Chem. Lett. Vol.43, 916-918, 2014.

[5] P. Qin, S. Paek, M. I. Dar, N. Pellet, J. Ko, M. Grätzel, M. K. Nazeeruddin, Perovskite solar cells with $12.8 \%$ efficiency by using conjugated quinolizino acridine based hole transporting material, J. Am. Chem. Soc. Vol.136, 8516-8519, 2014.

[6] P. Qin, S. Tanaka, S. Ito, N. Tetreault, K. Manabe, H. Nishino, M. Khaja, M. Grätzel, Inorganic hole conductor-based lead halide perovskite solar cells with $12.4 \%$ conversion efficiency, Nat. Commun. Vol.5, 3834-1-6, 2014.

[7] N. J. Jeon, J. H. Noh, Y. C. Kim, W. S. Yang, S. Ryu, S. I. Seok, Solvent engineering for high-performance inorganicorganic hybrid perovskite solar cells, Nat. Mater. Vol.13, 897-903, 2014.

[8] D. Shi, V. Adinolti, R. Comin, M. Yuan, E. Alarousu, A. Buin, Y. Chen, S. Hoogland, A. Rothenberger, K. Katsiev, Y. Losovyj, X Zhang, P. A. Dowben, O. F. Mohammed, E. H. Sargent, O. M. Bakr, Solar cells. Low trap-state density and long carrier diffusion in organolead trihalide perovskite single crystals, Science Vol.30, 519-522, 2015.

[9] J. H. Im, I. H. Jang, N. Pellet, M. Grätzel, N. G. Park, Growth of $\mathrm{CH}_{3} \mathrm{NH}_{3} \mathrm{PbI}_{3}$ cuboids with controlled size for high-efficiency perovskite solar cells, Nature Nanotech. Vol. 9, 927-932, 2014.

[10] X. Li, D. Bi, C. Yi, J. D. Décoppet, J. Luo, S. M. Zakeeruddin, A. Hagfeldt, M. Grätzel, A vacuum flash-assisted solution process for high-efficiency large-area perovskite solar cells, Science, Vol.353, 58-62, 2016.

[11] L. Cojocaru, S. Uchida, A. K. Jena, T. Miyasaka, J. Nakazaki, T. Kubo, H. Segawa, Determination of chloride content in planar $\mathrm{CH}_{3} \mathrm{NH}_{3} \mathrm{PbI}_{3-\mathrm{x}} \mathrm{Cl}_{\mathrm{x}}$ solar cells by chemical analysis Chem. Lett. Vol.44, 1089-1091, 2015.

[12] E. Edri, S. Kirmayer, M. Kulbak,, G. Hodes, D. Cahen, Chloride inclusion and hole transport material doping to improve methyl ammonium lead bromide perovskite-based high open-circuit voltage solar cells, J. Phys. Chem. Lett. Vol.5, 429-433, 2014.

[13] Q. Chen, H. Zhou, Y. Fang, A. Z. Stieg, T. B. Song, H. H. Wang, X. Xu, Y. Liu, S. Lu, J. You, P. Sun, J. McKay, M. S. Goorsky, Y. Yang, The optoelectronic role of chlorine in $\mathrm{CH}_{3} \mathrm{NH}_{3} \mathrm{PbI}_{3}(\mathrm{Cl})$-based perovskite solar cells, Nat. Commun. Vol.6, 7269, 2015.

[14] Y. Xu, L. Zhu, J. Shi, S. Lv, X. Xu, J. Xiao, J. Dong, H. Wu, Y. Luo, D. Li, Q. Meng, Efficient hybrid mesoscopic solar cells with morphology-controlled $\mathrm{CH}_{3} \mathrm{NH}_{3} \mathrm{PbI}_{3-\mathrm{x}} \mathrm{Cl}_{\mathrm{x}}$ derived from two-step spin coating method, ACS Appl. Mater. Interfaces, Vol.7, 2242-2248, 2015.

[15] J. Qing, H. T. Chandran, Y. H. Cheng, X. K. Liu, H. W. Li, S. W. Tsang, M. F. Lo, C. S. Lee, Chlorine incorporation for enhanced performance of planar perovskite solar cell based on lead acetate precursor, ACS Appl. Mater. Interfaces, Vol.7, 23110-23116, 2015.

[16] L. Dimesso, M. Dimamay, M. Hamburger, W. Jaegermann, Properties of $\mathrm{CH}_{3} \mathrm{NH}_{3} \mathrm{PbX}_{3}(\mathrm{X}=\mathrm{I}, \mathrm{Br}, \mathrm{Cl})$ powders as precursors for organic/inorganic solar cells, Chem. Mater. Vol.26, 6762-6770, 2014.

[17] S. Dharani, H. A. Dewi, RR. Prabhakar, T. Baikie, C. Shi, D. 
Yonghua, N. Mathews, P. P. Boix, S. G. Mhaisalkar, Incorporation of $\mathrm{Cl}$ into sequentially deposited lead halide perovskite films for highly efficient mesoporous solar cells, Nanoscale, Vol.6, 13854-13860, 2014.

[18] T. Shi, W. J. Yin, F. Hong, K. Zhu, Y. Yan, Unipolar self-doping behavior in perovskite $\mathrm{CH}_{3} \mathrm{NH}_{3} \mathrm{PbBr}_{3}$, Appl. Phys. Lett. Vol.106, 103902, 2015.

[19] J. Feng, B. Xiao, Effective Masses and Electronic and Optical Properties of nontoxic $\mathrm{MASnX}_{3}(\mathrm{X}=\mathrm{Cl}, \mathrm{Br}$, and I) perovskite structures as solar cell absorber: A theoretical study using HSE06, J. Phys. Chem. C Vol.118, 19655-19660, 2014.

[20] D. P. McMeekin, G. Sadoughi, W. Rehman, G. E. Eperon, M. Saliba, M. T. Hörantner, A. Haghighirad, N. Sakai, L. Korte, B. Rech, M. B. Johnston, L. M. Herz, H. J. Snaith, A mixed-cation lead mixed-halide perovskite absorber for tandem solar cells, Science Vol.351, 151-155, 2016.

[21] C. Yi, J. Luo, S. Meloni, A. Boziki, N. A. Astani, C. Grätzel, S. M. Zakeeruddin, U. Röthlisberger, M. Grätzel, Entropic stabilization of mixed A-cation $\mathrm{ABX}_{3}$ metal halide perovskites for high performance perovskite solar cells, Energy Environ. Sci. Vol.9, 656-662, 2016.

[22] T. Oku, T. Iwata, A. Suzuki, Effects of Niobium Addition into $\mathrm{TiO}_{2}$ Layers on $\mathrm{CH}_{3} \mathrm{NH}_{3} \mathrm{PbI}_{3}$-based Photovoltaic Devices, Chem. Lett. Vol.44, 1033-1035, 2015.

[23] A. Suzuki, H. Okada, T. Oku, Role of bromine doping on the photovoltaic properties and microstructures of $\mathrm{CH}_{3} \mathrm{NH}_{3} \mathrm{PbI}_{3}$ perovskite solar cells, AIP Conf. Proc. Vol.1709, 020022, 2016.

[24] A. Suzuki, H. Okada, T. Oku, Fabrication and Characterization of $\mathrm{CH}_{3} \mathrm{NH}_{3} \mathrm{PbI}_{3-\mathrm{x}-\mathrm{y}} \mathrm{Br}_{\mathrm{x}} \mathrm{Cl}_{\mathrm{y}}$ Perovskite Solar Cells, Energies Vol.9, 376-1-11, 2016.

[25] B. A. Rosales, L. Men, S. D. Cady, M. P. Hanrahan, A. J. Rossini, J. Vela, Persistent dopants and phase segregation in organolead mixed-halide perovskites, Chem. Mater. Vol.28, 6848-6859, 2016.

[26] T. Oku, K. Suzuki, A. Suzuki, Effects of chlorine addition to perovskite-type $\mathrm{CH}_{3} \mathrm{NH}_{3} \mathrm{PbI}_{3}$ photovoltaic devices, J. Ceram. Soc. Japan. Vol.124, 234-238, 2016.

[27] S. Luo, W. A. Daoud, Crystal structure formation of $\mathrm{CH}_{3} \mathrm{NH}_{3} \mathrm{PbI}_{3-\mathrm{x}} \mathrm{Cl}_{\mathrm{x}}$ perovskite, Materials, Vol.9, 123, 2016.

[28] T. Oku, Y. Ohishi, A. Suzuki, Effects of antimony addition to perovskite-type $\mathrm{CH}_{3} \mathrm{NH}_{3} \mathrm{PbI}_{3}$ photovoltaic devices, Chem. Lett. Vol.45, 134-136, 2016.

[29] J. Saito, T. Oku, A. Suzuki, T. Akiyama, Fabrication and characterization of perovskite-type solar cells with $\mathrm{Nb}$-doped $\mathrm{TiO}_{2}$ layers, AIP Conf. Proc. Vol.1709, 020027, 2016.

[30] Y. Ohishi, T. Oku, A. Suzuki, Fabrication and characterization of perovskite-based $\mathrm{CH}_{3} \mathrm{NH}_{3} \mathrm{~Pb}_{1-\mathrm{x}} \mathrm{Ge}_{\mathrm{x}} \mathrm{I}_{3}, \mathrm{CH}_{3} \mathrm{NH}_{3} \mathrm{~Pb}_{1-\mathrm{x}} \mathrm{Tl}_{\mathrm{x}} \mathrm{I}_{3}$ and $\mathrm{CH}_{3} \mathrm{NH}_{3} \mathrm{~Pb}_{1-\mathrm{x}} \mathrm{In}_{\mathrm{x}} \mathrm{I}_{3}$ photovoltaic devices, AIP Conf. Proc. Vol.1709, 020020, 2016.

[31] W. J. Yin, J. H. Yang, J. Kang, Y. Yan, S. H. Wei, Halide perovskite materials for solar cells: a theoretical review, J. Mater. Chem. A. Vol.3, 8926-8942, 2015.

[32] M. Saliba, S. Orlandi, T. Matsui, S. Aghazada, M. Cavazzini, J. P. C. Baena, P. Cao, R. Scopelliti, E. Mosconi, H. Dahmen, F. De Angelis, A. Abate, A. Hagfeldt, G. Pozzi, M. Graetzel, M. K. Nazeeruddin, A molecularly engineered hole-transporting material for efficient perovskite solar cells, Nature Energy Vol.1, 15017, 2016.

[33] D. Bi, B. Xu, P. Gaod, L. Sun, M. Grätzele, A. Hagfeldt, Facile synthesized organic hole transporting material for perovskite solar cell with efficiency of $19.8 \%$, Nano Energy, Vol.23, 138-144, 2016

[34] P. Qin, S. Paek, M. I. Dar, N. Pellet, J. Ko, M. Grätzel, M. K. Nazeeruddin, Perovskite solar cells with $12.8 \%$ efficiency by using conjugated quinolizino acridine based hole transporting material, J. Am. Chem. Soc. Vol.136, 8516-8519, 2014.

[35] A. Suzuki, T. Kida, T. Takagi, T. Oku, Effects of hole-transporting layers of perovskite-based solar cells, Jpn. J. Appl. Phys. Vol.55, 02BF01-1-5, 2016.

[36] C. V. Kumar, G. Sfyri, D. Raptis, E. Stathatos, P. Lianos, Perovskite solar cell with low cost Cu-phthalocyanine as hole transporting material, RSC Adv. Vol.5, 3786-3791, 2015.

[37] G. Sfyri, C. V. Kumar, G. Sabapathi, L. Giribabu, K. S. Andrikopoulos, E. Stathatos, P. Lianos, Subphthalocyanine as hole transporting material for perovskite solar cells, RSC Adv. Vol.5, 69813-69818, 2015.

[38] F. J. Ramos, M. Ince, M. Urbani, A. Abate, M. Grätzel, S. Ahmad, T. Torres, M. K. Nazeeruddin, Non-aggregated $\mathrm{Zn}$ (II)octa(2,6-diphenylphenoxy) phthalocyanine as a hole transporting material for efficient perovskite solar cells, Dalton Trans. Vol.44, 10847-10851, 2015.

[39] W. Ke, D. Zhao, C. R. Grice, A. J. Cimaroli, G. Fang, Y. Yan, Efficient fully-vacuum-processed perovskite solar cells using copper phthalocyanine as hole selective layers, J. Mater. Chem. A. Vol.3, 23888-23894, 2015.

[40] G. Sfyri, C. V. Kumar, Y. L. Wang, Z. X. Xu, C. A. Krontiras, P. Lianos, Tetra methyl substituted $\mathrm{Cu}$ (II) phthalocyanine as alternative hole transporting material for organometal halide perovskite solar cells, Appl. Surf. Sci. Vol.360, 767-771, 2016.

[41] F. Zhang, X. Yang, M. Cheng, W. Wang, L. Sun, Boosting the efficiency and the stability of low cost perovskite solar cells by using $\mathrm{CuPc}$ nanorods as hole transport material and carbon as counter electrode, Nano Energy, Vol.20, 108-116, 2016.

[42] W. Ke, D. Zhao, C. R. Grice, A. J. Cimaroli, G. Fang, Y. Yan, Efficient fully-vacuum-processed perovskite solar cells using copper phthalocyanine as hole selective layers, J. Mat. Chem. A. Vol.3, 23888-23894, 2015.

[43] M. Hiramoto, K. Kitada, K. Iketaki, T. Kaji, Near infrared light driven organic $\mathrm{p}-\mathrm{i}-\mathrm{n}$ solar cells incorporating phthalocyanine J-aggregate, Appl. Phys. Lett. Vol.98, 023302, 2011.

[44] M. Iwase, A. Suzuki, T. Akiyama, T. Oku, Fabrication and characterization of organic solar cells using titanyl phthalocyanine as hole transport layer, Phys. Status Solidi A Vol.211, 2861-2864, 2014.

[45] B. H. Lessard, J. D. Dang, T. M. Grant, D. Gao, D. S. Seferos, T. P. Bender, Bis(tri-n-hexylsilyl oxide) Silicon Phthalocyanine: A unique additive in ternary bulk heterojunction organic photovoltaic devices, Appl. Mater. Inter. Vol.6, 15040-15051, 2014.

[46] T. Oku, S. Hori, A. Suzuki, T. Akiyama, Y. Yamasaki, Fabrication and characterization of PCBM: P3HT: silicon phthalocyanine bulk heterojunction solar cells with inverted structures, Jpn. J. Appl. Phys. Vol.53, 05FJ08-1-5, 2014. 